\title{
Prática mídia-educativa na cultura digital: análise da produção de mapa mental com dispositivo móvel por estudantes do ensino fundamental
}

\author{
Sandra Dias da Luz - PMF - sandraluz.pmf@gmail.com \\ Dulce Márcia Cruz - CED/MEN/UFSC - dulce.marcia@gmail.com
}

\begin{abstract}
Resumo. Este artigo reflete sobre uma prática de mídia-educação que visou ampliar os letramentos de estudantes através da apropriação de linguagens, ferramentas e lógica da cultura digital no contexto escolar. A pesquisa-ação envolveu uma professora de Português e seus 72 estudantes do $9^{\circ}$ Ano do Ensino Fundamental de uma escola pública em duas oficinas de produção de mapa mental como recurso pedagógico de auxílio na análise, síntese e organização do conhecimento crítico com dispositivos móveis. A prática pedagógica alcançou as três dimensões da mídia-educação, mas revelou que possuir equipamento e ter acesso à internet não implica uso crítico das mídias por parte dos estudantes, assim como as práticas docentes não preparam os alunos para a autonomia e cidadania participativa, revelando distância da mídiaeducação e de suas respectivas dimensões.
\end{abstract}

Palavras-chave: Mídia-Educação, dispositivos móveis, multiletramentos, mapa mental, cultura digital, ensino fundamental

\section{Media-educational practice in digital culture: analysis of the production of mental map with mobile device by primary school students}

Abstract. This article reflects on a media-education practice action aimed at broadening student literacy through the appropriation of languages, tools and logic of digital culture in the school context. The action research involved a Portuguese teacher and her 72 students from the 9th grade elementary school of a public school in two mental map production workshops as a pedagogical aid in the analysis, synthesis and organization of critical knowledge with mobile devices. Pedagogical practice reached the three dimensions of media-education, but revealed that having equipment and having access to the internet does not imply critical use of the media by the students, even as in formal education, teaching practices do not prepare students for autonomy and for participatory citizenship, revealing distance from the media and their respective dimensions.

Keywords: Media-Education, mobile devices, multiliteracies, mental map, digital culture, elementary school.

\section{INTRODUÇÃO}

O problema abordado neste texto está ligado à necessidade de um enfoque globalizante da mídia-educação no que tange a conseguir cumprir suas três dimensões (educar com, sobre e através das mídias) considerando os estudantes sujeitos ativos e com habilidades em práticas midiáticas, mas, por outro lado, carentes de uma ação educativa formal que amplie seus letramentos, com a apropriação de linguagens, ferramentas e a lógica da cultura digital no contexto escolar.

O pressuposto do texto é que, para estar letrado na cultura digital, não basta ter acesso aos equipamentos, é preciso também compreender o meio, as mensagens e conseguir participar dele, produzindo e lendo conteúdos multimodais de forma crítica (TUFTE; CHRISTENSEN, 2009). Buckingham (2010) defende uma visão mais crítica, fazendo analogia entre o ensino e as mídias. Segundo ele, as mídias de massa 
representam a educação centrada na transmissão da informação; e as mídias digitais, o reverso, a educação centrada no aluno/usuário. Com a fragmentação dos canais, dos conteúdos, das mensagens e, portanto, do poder e do controle, reafirma-se a necessidade de se fazer mídia-educação para todos, alunos e professores. A possibilidade criada pelas mídias digitais do aluno tornar-se também produtor torna urgente a necessidade de prepará-los para serem não apenas críticos e criativos, mas também produtivos. E essa deveria ser a preocupação da escola e dos educadores na contemporaneidade. $O$ aumento do uso dos dispositivos móveis, por exemplo, e a dificuldade que a escola tem de lidar com sua chegada nas práticas midiáticas dos estudantes é um problema a ser resolvido. No entanto, no Brasil, a literatura continua mostrando exaustivamente (QUARTIERO; SOUZA, 2014; ALMEIDA, 2004) que as iniciativas que consideram a complexidade da cultura digital não são a regra nem estão sistematizadas, sendo privilegiadas as iniciativas governamentais verticalizadas, baseadas na mera compra de equipamentos e em sua entrega, sem crítica nem condições estruturais, tampouco formação docente suficiente para o uso nas escolas.

Nesse contexto, a proposta de mídia-educação na cultura digital se volta para buscar esses letramentos de modo mais complexo e abrangente.

Para verificar se uma prática mídia-educativa nesses termos conseguiria alcançar este objetivo, o presente artigo irá refletir sobre a mídia-educação à luz da cultura digital, em um breve percurso histórico e conceitual, analisando uma experiência realizada em duas oficinas de uso de dispositivos móveis com estudantes do Ensino Fundamental, em aulas de Português. As práticas analisadas aqui fizeram parte de uma investigação mais ampla, defendida por Luz (2017) em sua dissertação de mestrado.

\section{Breve histórico da mídia-educação}

É difícil precisar quando as mídias passaram a se destacar na Educação como meios de comunicação. Uma revisão dos textos sobre o campo, permite uma perspectiva plural e atual do contexto da mídia-educação. Nessas publicações, é possível verificar como o campo foi se constituindo em área de conhecimento e também como as suas dimensões de atuação - objeto de estudo (leitura crítica sobre a mídia), ferramenta pedagógica (uso instrumental com a mídia) e mais atual, a expressiva-produtiva-reflexiva (através da mídia) - foram se transformando, conforme os avanços tecnológicos de cada período, tendo a mídia-educação acompanhado essa mudança. As referências que percorrem a evolução tecnológica e as mudanças na Educação observadas desde a popularização dos meios de comunicação, tais como o cinema, a fotografia, o rádio e o jornal impresso, datam do início do século XX. Nessa interlocução, a mídia-educação diferencia a relação entre a mídia e a educação em diferentes fases, chamadas de inoculatória, leitura crítica, ideológica e pensamento crítico (RIVOLTELLA, 2012).

A fase inoculatória, observada em países como Estados Unidos e Grã-Bretanha, nasceu sob o baluarte da proteção aos espectadores. Nessa primeira fase, a escola foi se formando como um espaço de resistência a esses meios de cultura inferior (FANTIN, 2006). Na segunda perspectiva, da leitura crítica, cunhada nas décadas de 1950 e 1960 na Europa, Estados Unidos e Canadá, houve o consenso de que as mídias educam. Ao mesmo tempo, as mídias passaram a ser utilizadas para a educação de grandes públicos - como nos telecursos -, mas as mensagens contidas em cinema, rádio, televisão e jornal impresso careciam de serem lidas com um olhar mais apurado, o que exigiu da escola uma nova postura, especialmente por parte dos educadores, a fim de promover uma leitura crítica dos meios (BELLONI, 2001). Em países da América Latina, especialmente no Brasil das décadas de 1970 e 1980, a fase ideológica da mídiaeducação exerceu o importante papel de proporcionar comunicação alternativa às 
classes menos favorecidas, configurando-se numa concepção de contracultura. A perspectiva do pensamento crítico é a concepção mais atual da mídia-educação e consiste no encontro da didática, com a semiótica, a sociologia e a análise de consumo. Desde então, as produções midiáticas escritas passaram a serem lidas e produzidas como linguagem, na qual o meio, a mensagem e o formato se distinguem, promovendo a diversidade cultural (BÉVORT; BELLONI, 2009).

As perspectivas descritas até aqui serviram para marcar a mídia-educação como campo de intersecção entre as mídias e a educação. Na década de 1990, a Organização das Nações Unidas para a Educação, Ciência e Cultura (UNESCO, 1999, p. 2) recomendou que a "[...] mídia-educação deveria abordar todos os tipos de textos, presentes em todas as mídias (escritas, imagens, áudio e imagem em movimento) proporcionando às pessoas experiências culturais ricas e diversas". Essas orientações reconheciam que o conhecimento não pode ser expresso pela linearidade da palavra escrita, valorizada historicamente nos livros, e que a alfabetização, como codificação destes códigos escritos, não alcança a complexidade de ler, escrever, compreender e socializar neste contexto. Os avanços tecnológicos e a miniaturização dos equipamentos no final do século XX aumentaram o acesso e o consumo de mídias pela população, possibilitando a conexão entre pessoas de todo planeta.

Estar conectado é condição que expressa a cultura digital. Essa nova forma de ser, pensar e agir está relacionada ao fato de que, "[...] ao propiciar outras formas de interação, socialização e transmissão simbólica, a cultura digital participa de nossa prática sociocultural na produção e socialização de conhecimentos e na construção de significados de nossa inteligibilidade do mundo" (FANTIN, 2012, p. 98). Esta realidade de tecnologias do acesso, a Web 1.0, foi instaurada com o surgimento de máquinas que permitiram a convergência dos computadores com as telecomunicações, dando início a uma nova fase de aproximação entre o homem e a máquina, com a qual formaram-se redes de relacionamentos virtuais que provocam deslocamentos no tempo e no espaço.

Diante de uma nova realidade conectada, que permitiu "[...] a convergência dos computadores com as telecomunicações" (SANTAELLA, 2007, p. 198), a chamada Web 1.0, novas mídias foram propagadas e diferentes abordagens educacionais sobre este cenário se fizeram necessárias. As possibilidades de alfabetização/letramento multimodal levantadas a partir dos anos 2002, quando surge a Web 2.0, expressam essa condição. A Web 2.0 foi desenvolvida com o objetivo de proporcionar a comunicação entre usuários, tendo como base a conectividade entre pessoas. A Web 2.0 tornou possível aos indivíduos produzir e publicar conteúdo digital em diferentes formatos: texto, podcast, imagem e vídeo, ampliando os desafios da educação atual.

Como resultado das modificações promovidas nas esferas social, econômica, política, cultural e escolar pela cultura digital, a Unesco reúne-se novamente, a fim de formular definições mais recentes, as quais percorreram os cinco continentes, resultando na Agenda de Paris 2007 e, posteriormente, na Carta de Mídia-Educação, de 2008. Nesses documentos, a inclusão digital foi acrescida à concepção de mídia-educação, não como sinônimo apenas de acesso, mas sim de participação e liberdade de expressão nos meios digitais. Nas referidas publicações, também foi recomendado prioritariamente a adoção da mídia-educação no ensino formal, na formação inicial dos professores e como área de pesquisa.

Dessa forma, com definições mais próximas à realidade da cultura digital, o objetivo geral da mídia-educação atualmente pode ser resumido nos seguintes elementos: "[...] comunicação; busca de informação; percepção, análise e avaliação da produção profissional de mídia; produção, análise e avaliação da produção de mídia dos estudantes" (TUFTE; CHRISTENSEN, 2009, p. 104). 
Assim, o trabalho com a mídia-educação, campo que une conceitos oriundos de duas áreas, Comunicação e Educação, apesar de ter iniciado há um século, ainda é algo a ser conquistado. Torna-se impensável falar em educação para a cidadania sem a compreensão de que a comunicação é indissociável da prática pedagógica. Numa sociedade plural, na qual é cada vez maior a possibilidade de acesso à informação, são necessárias a inclusão e a participação de todos os indivíduos, para que, dessa forma, a escola possa se tornar um lugar em que se aprenda com autonomia, criatividade e autoria.

\section{As dimensões da mídia-educação na cultura digital}

$\mathrm{Na}$ abordagem da mídia-educação, três dimensões se completam e expressam a natureza do objeto: o objeto de estudo, a ferramenta pedagógica e a apropriação das mídias como meios ou ferramentas de expressão e participação ou, em outros termos, com, sobre e através das mídias.

Com a mídia implica educar usando-a como ferramenta. Sobre a mídia, “[...] diz respeito à apropriação crítica sobre os conteúdos, sobre as mensagens", enquanto através da mídia está ligada ao educar para aprimorar a "[...] habilidade de produção na escola" (RIVOLTELLA, 2012, p. 23, grifos do autor). Assim, a educação com as mídias na cultura digital pode ser utilizada por professores e estudantes no sentido de substituir antigos recursos didáticos ou trazer à sala de aula ferramentas novas, a fim de subsidiar a ilustração do conteúdo.

A educação para/sobre as mídias ou como objeto de estudo tem por objetivo "[...] desenvolver competências para a análise crítica de mensagens, seja em notícias, entretenimento, a fim de reforçar as capacidades dos indivíduos autônomos e usuários ativos" (UNESCO, 2007, p. 2). Para Buckingham (2008, p. 4), “[...] isso implica que a educação sobre a mídia é um pré-requisito indispensável para a educação com ou através da mídia". Se as mídias educam por meio de suas mensagens, conteúdos e formas, é necessário trazê-las para a realidade da escola e desenvolver a capacidade do aluno de lê-las criticamente. Ou ainda, como ressalta Belloni (2001, p. 46), enquanto objeto de estudo, deve-se fornecer "[...] às crianças e adolescentes os meios de dominar esta nova linguagem".

A terceira dimensão da mídia-educação, através, é expressa com o objetivo de "[...] incentivar a produção, a criatividade e interatividade nas diferentes áreas da mídia e comunicação" (UNESCO, 2007, p. 2) diante da popularização da internet. A autoria midiática possibilitada pelas tecnologias digitais é permeada pela produção de significados. Em cada imagem, vídeo, som ou texto que se insere numa mensagem há uma tessitura de elementos para que a informação, editada de forma fragmentada, seja decodificada pelo espectador, construindo diferentes significados. A partir da perspectiva da mídia-educação, o trabalho pedagógico com as mídias na cultura digital se torna "[...] indispensável para o exercício da cidadania, ou seja, para estimular a participação ativa dos jovens baseada na valorização das diversidades culturais e identitárias" (FANTIN, 2012, p. 53). A partir desta definição da dimensão da mídiaeducação, através, entende-se que a formação de sujeitos expressivos, produtivos, críticos e reflexivos envolve principalmente a utilização da linguagem como produtora de significados, suscitando a construção do conhecimento de forma crítica e criativa com o uso das mídias, em consonâncias com às exigências de letramento na contemporaneidade. Esse enfoque globalizante foi a base da pesquisa aqui descrita. 


\section{MATERIAL E MÉTODOS}

A metodologia descrita a seguir busca remontar o processo empírico, integrado à disciplina de Português, que teve como objetivo propor a produção de mapa mental em dispositivo móvel, desenvolvido durante duas oficinas com estudantes do $9^{\circ}$ Ano de uma escola pública. Essa produção faz parte de uma pesquisa de mestrado (LUZ, 2017) de natureza aplicada, por considerar as descobertas observadas na experiência no campo; e de finalidade descritiva, por relatar a integração das tecnologias móveis à prática educativa, que se utilizou da estratégia pesquisa-ação, tendo realizado, no total, 18 oficinas práticas de intervenção investigativa. A análise de dados foi feita de forma qualitativa, utilizando diferentes estratégias de investigação, métodos de coleta, análise e interpretação do estudo de caso sobre a integração de dispositivos móveis no contexto real de uma disciplina curricular (SEVERINO, 2007).

O universo da pesquisa, realizada no ano de 2017, é composto por 762 alunos e 39 professores de uma escola pública da Rede Municipal de Ensino de Florianópolis. Os sujeitos da amostra foram as duas turmas de $9^{\circ}$ Ano do Ensino Fundamental, formada por 72 estudantes e pela professora de Português. Para o levantamento de dados, recorreu-se à observação in loco e à coleta de informações por meio de um questionário online, composto por 24 questões, com as quais se constatou o amplo uso de smartphones pelos estudantes em atividades correlatas ao entretenimento e pouca aderência ao uso da tecnologia móvel para aprendizagem (LUZ; CRUZ, 2017).

A inserção planejada para o campo consistiu em uma prática de mídia-educação na cultura digital, a partir da proposição do uso do dispositivo móvel para produção de um mapa mental sobre um conto de Machado de Assis, estudado na disciplina de Português. $\mathrm{Na}$ atividade, os estudantes deveriam analisar a estrutura narrativa do texto e apresentar como síntese um mapa mental, construído com um aplicativo digital em dispositivo móvel.

A atividade foi pensada de maneira a fazer com que a análise de dados pudesse identificar as dimensões da mídia-educação (ferramenta pedagógica - uso instrumental com a mídia; objeto de estudo - leitura crítica sobre a mídia; e expressiva-produtivareflexiva - através da mídia) mobilizadas no modo com o qual os estudantes fizeram uso de dispositivo móvel, apontando as dificuldades que tiveram ao realizá-la. Dessa forma, as categorias de análise elencadas foram: 1) com, 2) sobre e 3) através da mídiaeducação, constatadas na produção e no relato dos estudantes, bem como por observação direta.

A justificativa para essa prática de uso da ferramenta mapa mental leva em conta que os estudantes foram instigados a substituir uma tecnologia - papel e caneta - por outra - o aplicativo - mais próxima à sua cultura, haja vista ser "[...] um recurso para a educação reinventar a didática ensinando com outros meios, visando superar o esquema tradicional e substituir o suporte do livro-texto" (FANTIN, 2006, p. 85).

\section{DESCRIÇÃO E ANÁLISE DOS RESULTADOS}

Sob a ótica da mídia-educação, o objetivo da pesquisa foi investigar como seria uma prática educativa que gerasse a produção de mapas mentais com, sobre e através de dispositivos móveis. No entanto, para analisar essa prática educativa, é preciso primeiro discutir as dificuldades que antecedem a execução da proposta. Isso porque os desafios que foram colocados interferiram na prática e precisam ser considerados também como variáveis das condições de execução da pesquisa. Tais desafios podem ser apresentados sob a forma de questões a que tentaremos responder a seguir: quais os tempos e os espaços na escola que atendem a questão do acesso à internet? Quais equipamentos seriam utilizados, os próprios smartphones ou os tablets da escola? 
Apesar de possuir uma estrutura com alguns pontos de internet, o auditório da escola foi utilizado na primeira oficina, deixando o disputado espaço impossibilitado a outras turmas. Para a segunda oficina, no entanto, a sala informatizada foi o local disponível para a prática, chocando duas tecnologias, a móvel e a fixa em um mesmo espaço. A limitação do sinal da internet fez com que a senha também fosse restrita aos professores. A forma como a internet está pensada nessa escola exemplifica como o acesso aos equipamentos e à conexão se mostram insuficientes para a prática pedagógica na cultura digital.

Em relação aos equipamentos, os alunos foram deixados livres para escolha de qual usar: smartphone ou tablet. Mesmo tendo os seus dispositivos particulares, os alunos, entusiasmados, pegaram os tablets, fruto de um projeto do governo estadual de difusão desses dispositivos para a prática educacional (LUZ, 2017). No entanto, empoeirados, sem configuração ou bateria, os tablets denunciaram a falta de uso dos equipamentos recebidos há mais de um ano.

$\mathrm{Na}$ tentativa de suprir essas barreiras, a senha do wi-fi foi liberada para os alunos, tanto em seus equipamentos quanto nos fornecidos pela Unidade. Nesse instante outro problema se revelou: a internet não suporta a conexão de 35 aparelhos conectados simultaneamente. Diante de repetidos problemas acerca do acesso à internet, há que se questionar: que práticas mídias-educativas são possíveis? A solução encontrada foi limitar o acesso a um equipamento por grupo de trabalho. Esta pseudoconexão não garante acesso a todos. Apesar de ser um pequeno avanço, ainda não é suficiente para iniciar um processo de inclusão digital de estudantes do Ensino Fundamental. As dificuldades encontradas pelos alunos e a apropriação da prática pela professora diante desta nova abordagem fizeram com que a atividade se estendesse por mais um encontro.

Após essa contextualização do cenário da pesquisa, passamos a descrever e analisar a prática pedagógica desenvolvida nas oficinas que foi embasada nas três dimensões da mídia-educação (objeto de estudo, ferramenta pedagógica e expressãoprodução-reflexão). A primeira oficina que trabalhou o texto foi planejada para abordar a estrutura narrativa. O gênero utilizado foi o conto psicológico, do qual os alunos estudaram: enredo (o que), o narrador (quem conta), os personagens (sobre quem), o tempo (como), o espaço (onde) e o episódio recordado (lembrança). No primeiro momento, foi exibido em sala de aula o vídeo ${ }^{1}$ da obra $O$ Alienista, de Machado de Assis. Após assistir ao vídeo, os alunos recontaram oralmente a história de modo que estivesse presente a estrutura narrativa: o que, quem conta, sobre quem, como, onde e a lembrança. Na sequência, foram destacados os recursos de mídia utilizados para narrar a história: visual, sonoro, textual e gestual. Observando-se esse primeiro momento, constatou-se que, oralmente e em grande grupo, os estudantes conseguiram perceber os elementos da estrutura narrativa, bem como a mídia utilizada para contar a história.

Os estudantes, divididos em 12 grupos, seis em cada turma, foram instigados a organizar e sistematizar o conhecimento sobre narrativa por meio de um mapa mental. Segundo Saccol, Schlemmer e Barbosa (2011, p. 72), os mapas "[...] revelam a pluralidade e compatibilidade ou incompatibilidade de perspectiva em determinado contexto" e, por essa razão, foram utilizados para organização do conhecimento e posicionamento crítico. Para a construção dos mapas, os estudantes poderiam utilizar qualquer aplicativo móvel, mas foram sugeridos o simplemindfree ${ }^{2}$ e o mindly ${ }^{3}$. Com o intuito de sistematizar a estrutura narrativa do conto, os estudantes receberam como tarefa de casa a produção de um mapa mental, produzido com o aplicativo da sua escolha, no qual esperava-se que discutissem os elementos da narrativa $\mathrm{e}$ compartilhassem a síntese da discussão com a turma por meio de um grupo virtual no WhatsApp, especialmente criado para a oficina. 
Para a segunda oficina, quatro dos doze grupos conseguiram compartilhar o mapa pelo WhatsApp (Figura 1). Diante da falta de questionamento por parte dos alunos sobre o que é um mapa ou como poderiam fazê-lo, as dúvidas foram acolhidas no grupo da turma no WhatsApp, repetindo-se informações já fornecidas em sala de aula.
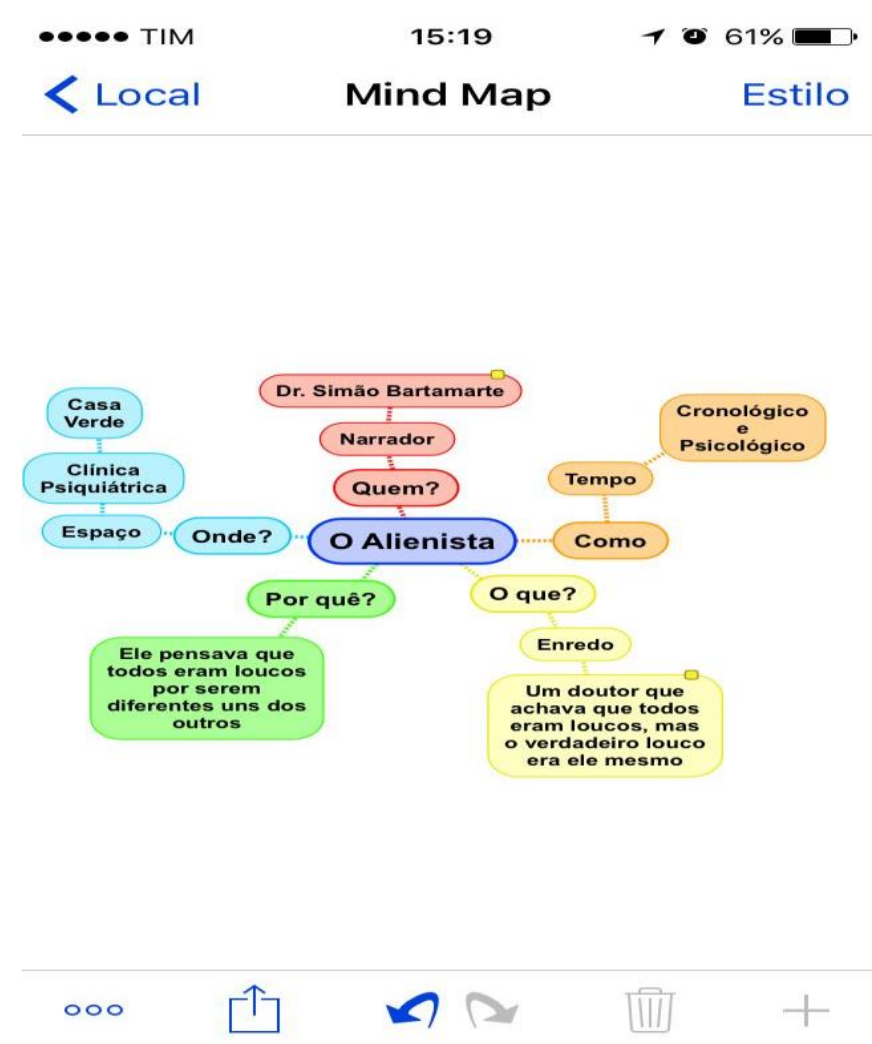

Figura 1 - Exemplo de mapa mental produzido pelos estudantes durante as oficinas utilizando aplicativo Simplemindfree

No início da segunda oficina, a discussão girou em torno do questionamento sobre o aplicativo como objeto de estudo. Os quatro grupos que entregaram a tarefa escolheram o primeiro aplicativo na lista do Play Store: SimpleMindFree, revelando um consumo acrítico da mídia. Os grupos que não entregaram a tarefa argumentaram não ter compreendido como fazer ou alegaram a falta de dispositivo que suportasse o aplicativo. A perspectiva do uso como objeto de estudo, com vistas "[...] a saber compreender, interpretar e avaliar os conteúdos das diversas mídias" (FANTIN, 2006, p. 86), serviu como base para que fossem analisadas, com a participação dos estudantes, as características do aplicativo. Os alunos consideraram bom o aplicativo SimpleMindFree no tocante ao tamanho e facilidade de manuseio, mas apontaram limites como a não possibilidade de escrita cooperada e restrições ao compartilhamento do mapa pronto. Enriquecendo a discussão, a professora apresentou vários sites, tutoriais e vídeos que poderiam ter sido utilizados como fontes de pesquisa para compreensão do aplicativo.

$\mathrm{Na}$ segunda parte dessa oficina, um grupo explicou como venceu a dificuldade de compartilhamento fazendo print da tela do celular, demonstrando, através da mídia (ou seja, de forma produtiva), uma apropriação da “[...] concepção alfabética e expressiva, objetivando a interação dos sujeitos com as mídias e promovendo o conhecimento criativo e também crítico de suas linguagens" (FANTIN, 2006, p. 86). O mapa mental de um dos grupos foi projetado na lousa, a fim de que se discutisse 
coletivamente a sua produção. Na correção coletiva, a professora enfatizou questões específicas do conteúdo de Português. Houve necessidade de reescrever o mapa mental considerando as inconsistências apontadas pela correção coletiva. Finalizando a oficina, a professora solicitou outras duas atividades com o uso do mapa mental, para as quais dez grupos optaram pelos aplicativos SimpleMindFree ou Mindly, um utilizou-se do computador e o outro permaneceu fazendo à mão.

A pesquisa sobre o que é mapa mental e como se produz poderia ter sido realizada fora da escola, uma vez que os estudantes afirmaram possuir acesso à internet, mas também não foi aproveitado esse potencial de ampliação da sala de aula. $O$ fato de o aplicativo ter sido escolhido apenas por estar no topo do Play Store, mesmo não atendendo às necessidades do trabalho em grupo, pode não apenas revelar a falta de comprometimento por parte dos alunos mas também denotar um consumo acrítico da mídia, reiterando a constatação de que possuir o equipamento e ter acesso à internet não são suficientes para formação do cidadão participativo na cultura digital, além de dar mostras do quão distante está o ensino formal de abordar a mídia-educação e suas dimensões. Ao iniciar essa prática, constatou-se que os alunos fizeram uso do primeiro aplicativo que apareceu no Play Store, sem refletir sobre suas limitações e possibilidades. Os alunos que não baixaram aplicativos ficaram esperando o próximo encontro, para que a professora lhes explicasse o que deveria ser feito. Nessa prática pedagógica, o uso da tecnologia não foi empregado de forma neutra.

\section{CONSIDERAÇÕES FINAIS}

A ação pedagógica proposta, em sua simplicidade, possibilitou que os estudantes desenvolvessem uma postura mais ativa para construir e compartilhar o conhecimento de forma colaborativa. Dessa forma, com um cenário pouco favorável, as oficinas buscaram integrar o uso do dispositivo móvel à prática pedagógica nas aulas de Português. O propósito era de que, ao inserir o dispositivo móvel nas oficinas, seu uso se tornasse transparente e natural, como ocorre com outras tecnologias embutidas em nosso dia a dia, como a luz elétrica. Um respiro necessário, considerando que somente quando garantida, no mínimo, a inserção da tecnologia móvel em práticas pedagógicas dentro do ensino formal é que se pode abrir a discussão sobre a mídia-educação e suas dimensões na cultura digital.

No entanto, como conclusão sobre os resultados da oficina, constatou-se que os alunos esperaram pela explicação da professora sobre o que era para ser feito. $\mathrm{O}$ fato demonstra que, no processo de ensino e de aprendizagem em que os estudantes estão inseridos, as práticas docentes não formam alunos para desenvolverem-se autonomamente. Com isso, a ausência de explicação inicial levou à não realização da tarefa por parte de oito dos doze grupos. As dificuldades encontradas na falta de estrutura e de conexão não impossibilitaram a realização de uma prática pedagógica de acordo com as dimensões atuais da mídia-educação. Os estudantes foram instigados a refletir com, sobre e através da mídia na produção de um mapa mental. Essa abordagem se refletiu nas atividades subsequentes propostas pela professora, e, ao final do estudo da narrativa, dez grupos conseguiram escolher um aplicativo de forma crítica, uma outra equipe conseguiu argumentar com clareza o porquê de ter optado pelo computador. Essa consciência sobre a educação para as mídias reforça ainda mais a necessidade de se fazer sistematicamente mídia-educação na escola, integrando-se ao currículo a discussão sobre a comunicação, a pesquisa, a percepção, o consumo e a produção de conhecimento através das mídias. 


\section{NOTAS DE TEXTO}

${ }^{1}$ Vídeo produzido por estudantes denominado de book trailer, ou seja, um livro contado em formato de vídeo sobre a obra $O$ Alienista. Disponível em: <https://bit.ly/2JPNazc>. Acesso em: 11 out. 2017.

2 Aplicativo para dispositivo móvel que auxilia na criação de mapa mental. Disponível em: <https://bit.ly/1MQ7kqh>. Acesso em: 11 out. 2017.

3 Aplicativo para dispositivo móvel que auxilia na criação de mapa mental. Disponível em: <https://bit.ly/1FERcro>. Acesso em: 11 out. 2017.

\section{AGRADECIMENTOS}

Agradecemos ao Fundo de Apoio à Manutenção e ao Desenvolvimento da Educação Superior (Fumdes) pela bolsa de mestrado e ao Conselho Nacional de Desenvolvimento Científico e Tecnológico (CNPq) pela bolsa-produtividade, as quais deram suporte à realização desta pesquisa.

\section{REFERÊNCIAS}

ALMEIDA, Maria Elizabeth Bianconcini. Inclusão digital do professor: formação e prática pedagógica. São Paulo: Articulação, 2004.

BELLONI, Maria Luiza. O que é mídia-educação. 2. ed. Campinas: Autores Associados, 2001.

BÉVORT, Evelyne. BELLONI, Maria Luíza. Mídia-educação: conceitos, histórias e perspectivas. Educ. Soc., Campinas, v. 30, n. 109, p. 1081-1102, set./dez. 2009.

BUCKINGHAM, David. Aprendizagem e cultura digital. Revista Pátio, Porto Alegre, ano XI, n. 44, p. 8-11, jan. 2008. Disponível em: 〈https://goo.gl/K5q1kX>. Acesso em: 12 jul. 2017.

Cultura digital, educação midiática e o lugar da escolarização. Educação \& Realidade, Porto Alegre, v. 35, n. 3, p. 37-58, set./dez. 2010.

FANTIN, Mônica. Mídia-educação no currículo e na formação inicial de professores. In: FANTIN, Mônica; RIVOLTELLA, Pier Cesare (Orgs.). Cultura digital e escola: pesquisa e formação de professores. Campinas, SP: Papirus, 2012. p. 57-95.

FANTIN, Mônica. Mídia-Educação: conceitos, experiências, diálogos Brasil-Itália. Florianópolis: Cidade Futura, 2006.

LUZ, Sandra Dias da. Miradas no caleidoscópio: oficinas de multiletramentos com dispositivos móveis na criação de narrativas digitais na educação básica. Florianópolis: UFSC, 2017. 229 p. Dissertação (Mestrado). Disponível em: <http://www.bu.ufsc.br/teses/PEED1294-D.pdf>. Acesso em: 23 jul. 2018.

LUZ, Sandra Dias da.; CRUZ, Dulce Márcia. Aluno on, escola off-line: perfil de estudantes do Ensino Fundamental sobre aprendizagem móvel. In: SEMINÁRIO WEB CURRÍCULO: EDUCAÇÃO DIGITAL, 5. São Paulo, 16 a 18 de outubro de 2017. Anais eletrônicos... São Paulo: PUC, 2017. p. 329-337. Disponível em: Acesso em: <http://www.pucsp.br/webcurriculo/anais.html >. Acesso em: 11 jun. 2018. 
ORGANIZAÇÃO DAS NAÇÕES UNIDAS PARA A EDUCAÇÃO, CIÊNCIA E CULTURA (UNESCO). Educating for the Media and the Digital Age. Viena, Áustria: 20 abr. 1999. Disponível em: 〈https://bit.ly/2mzXmCX>. Acesso em: 12 jul. 2017.

Paris agenda or 12 recommendations for media education. [S.1], [2007]. Disponível em: <https://bit.ly/2jzqRkg>. Acesso em: 14 jul. 2016.

QUARTIERO, Elisa. Maria; SOUZA, Joseilda. S. O projeto UCA na Bahia e em Santa Catarina. In: QUARTIERO, Elisa. M; BONILLA, Maria Helena, FANTIN, Monica. Projeto UCA: Entusiasmo e Desencantos de uma Política Pública. Salvador: EdUFBA, 2015. p. 23-31.

RIVOLTELLA, Pier Cesare. Retrospectivas e tendências da pesquisa em mídiaeducação no contexto internacional. In: FANTIN, Mônica; RIVOLTELLA, Pier Cesare (Orgs.). Cultura digital e escola: pesquisa e formação de professores. Campinas, SP: Papirus, 2012. p. 17-30.

SACCOL, Amarolinda; SCHLEMMER, Eliane; BARBOSA, Jorge. M-learning e ulearning: novas perspectivas das aprendizagens móvel e ubíqua. São Paulo: Pearson Hall, 2011.

SANTAELLA, Lucia. Linguagens líquidas na era da mobilidade. São Paulo: Paulus, 2007.

SEVERINO, Antonio J. Metodologia do trabalho científico. 23. ed. São Paulo: Cortez, 2007.

TUFTE, Birgitte; CHRISTENSEN, Ole. Mídia-Educação - entre a teoria e a prática. Perspectiva, Florianópolis, v. 27, n. 1, p. 97-118, jan./jun. 2009. 